\title{
A AFETIVIDADE NAS RELAÇÕES DE ENSINO-APRENDIZAGEM ENTRE PROFESSOR E ALUNO
}

\author{
Amanda Patrícia de Araújo ${ }^{1}$ \\ Danna Beatriz da Silva Alves ${ }^{2}$ \\ Fernanda Santana da Silva ${ }^{3}$ \\ Stephanie de Oliveira Cavalcanti ${ }^{4}$ \\ Fabiana Maria da Silva ${ }^{5}$
}

\section{RESUMO}

A afetividade na relação professor-aluno tem sido vista como fundamental para o processo de ensino e aprendizagem na sala de aula, pois a mesma contribui de forma significativa para a construção do conhecimento e da autonomia do educando. O presente trabalho objetivou analisar a importância da afetividade nas relações de ensino-aprendizagem entre o professor e aluno. Trata-se de uma pesquisa qualitativa realizada a partir de um estudo bibliográfico, o qual foi produzido através da pesquisa e análise de artigos que tratassem sobre a afetividade no âmbito escolar. Deste modo, foi possível compreender os principais conceitos da afetividade e a importância dos vínculos afetivos. Os resultados nos mostraram as possíveis causas que dificultam a falta da afetividade na relação professor e aluno, e que essas situações podem desencadear outros fatores como uma má relação entre ambos, e dificuldades no processo de ensino-aprendizagem.

Palavras-chave: Afetividade. Educação. Relação professor-aluno.

Data de submissão: $27 / 05 / 2020$

Data de aprovação: $28 / 07 / 2020$

\section{INTRODUÇÃO}

Atualmente muito se discute sobre educação e seus desdobramentos. $\mathrm{O}$ debate sobre este tema é cada vez mais necessário, pois se sabe do seu poder de transformação da realidade. A contemporaneidade nos apresenta um cenário que, apesar dos avanços tecnológicos, surge cada vez com mais frequência. Conflitos sociais de várias naturezas estão presentes no âmbito escolar. Esse contexto de reflexão sobre a educação chama a atenção para o tema da afetividade, que é um aspecto relevante para o desenvolvimento e

\footnotetext{
${ }^{1}$ Graduanda do curso de Pedagogia da FMGR. E-mail: amandapatriciaxp_araujo@hotmail.com

2 Graduanda do curso de Pedagogia da FMGR.E-mail: dannabsa@gmail.com

3 Graduanda do curso de Pedagogia da FMGR. E-mail: fernanda55santanaa@gmail.com

4 Graduanda do curso de Pedagogia da FMGR. E-mail: tecyolive@hotmail.com

5 Professora orientadora do curso de Pedagogia da FMGR. E-mail: fabiana.silva1@gmail.com
} 
aprendizagem das crianças.

As crianças estão demandando cada vez mais atenção na escola, fato este que pode estar ligado ao aumento do ritmo de trabalho das pessoas, atualmente. A escola acaba por receber estudantes cuja relação afetiva com as famílias não é estabelecida, em muitos casos. Esse contexto nos leva a localizar a pertinência do estudo sobre a afetividade no ambiente escolar, e tentar compreender a afetividade na relação de ensino, estabelecida entre professor e aluno.

Com a contribuição de estudos de diferentes campos do conhecimento, a pesquisa discutirá a afetividade com base na teoria de autores como Jean Piaget, Lev Vygotsky e Henri Wallon, que já atribuíam importância à afetividade no processo evolutivo da criança. Na Pedagogia, Paulo Freire defende a tese de que "educar é um ato de amor".

Esses estudiosos afirmam a importância das relações afetivas na ação dos educadores. A afetividade pode estimular o processo de aprendizagem, favorecendo a relação do aluno com as disciplinas curriculares e com o próprio professor. Já a ausência da mesma aparece como fonte de dificuldades da aprendizagem dos alunos.

Esse tema foi escolhido porque acredita-se que a educação com afetividade é uma educação baseada no respeito, autonomia e compreensão. Diante de nossas experiências acadêmicas e profissionais, vimos que cada criança traz consigo, em sua história, problemas de comportamento, de relacionamento e de aprendizagem. Entretanto, um professor dedicado e preocupado com seus alunos é capaz de contribuir positivamente na resolução dos conflitos dos mesmos, que naturalmente vão se apresentar no cotidiano escolar. A afetividade na relação professor-aluno é um elemento básico no processo de ensino e aprendizagem, visto que a partir de um bom relacionamento entre o educador e o educando, em conjunto com um ambiente harmonioso, a criança se sente estimulada e segura para construir sua aprendizagem e autonomia.

O estudo apresenta uma breve discussão sobre a afetividade, que permitirá uma reflexão e análise a respeito da sua relevância nas relações de ensino-aprendizagem entre professor e aluno. Para dar conta do objetivo geral se faz necessário a análise da afetividade nas ações dos educadores, compreender os principais conceitos da afetividade, compreender a importância dos vínculos afetivos e compreender, a partir da produção acadêmica, possíveis fatores que dificultam a falta da afetividade na relação professor-aluno.

Para a realização dessa pesquisa foi adotada a abordagem qualitativa, sendo uma pesquisa de natureza básica, baseada como instrumento de pesquisa bibliográfica, no âmbito pedagógico, e na relação educativa estabelecida entre professor e aluno na sala de 
aula.

Pressupomos que se faz necessário que o professor tenha um olhar cauteloso, dentro da prática pedagógica, e compreenda a afetividade, percebendo que a mesma permite ao educando um diálogo entre o conhecimento e o afeto, contribuindo para a qualidade do processo de aprendizagem.

\section{FUNDAMENTAÇÃO TEÓRICA}

\section{Conceito da afetividade}

No campo da psicologia, a afetividade é a capacidade de reação por algum sujeito, diante de estímulos, sejam eles internos ou externos. Suas principais manifestações são os sentimentos e as emoções. Numa linguagem mais coloquial a afetividade se refere às demonstrações de amor, de carinho, que um ser apresenta a quem ama, a quem faz parte do seu ambiente.

A respeito do que venha a ser afetividade, vamos discorrer um pouco sobre o pensamento de Wallon (2010):

É possível pensar a afetividade como um processo amplo que envolve a pessoa em sua totalidade. Na constituição da estrutura da afetividade, contribuem de forma significativa as diferentes modalidades de descarga do tônus, as relações interpessoais e a afirmação de si mesmo, possibilitada pelas atividades de relação. (WALLON, 2010, p. 14).

A afetividade sempre ocorre em um contexto interativo, pois quem sente afeto pelo próximo é porque geralmente também recebe ou espera receber afeto do outro. Para Vygotsky, a emoção é a reflexão de estímulos que são atendidos no meio sociocultural em que o indivíduo está inserido. As emoções têm influência direta no comportamento de um indivíduo, ou seja, uma criança que recebe inúmeras demonstrações de bons sentimentos cresce como um adulto mais afetivo. Uma pessoa que cresceu num ambiente de pouco afeto, racionalmente será um indivíduo pouco afetivo.

A afetividade, apesar de ser um assunto de extrema importância na vida, é um tema pouco comentado no contexto escolar, mas tem sido visto como necessário para uma boa relação entre professores e alunos, trazendo benefícios para o desenvolvimento cognitivo do educando. 
Estamos diante de uma geração carente de afeto, em que é preciso que tenha alguém que olhe para elas com comprometimento, com formação de valores, e não simplesmente com a construção de conhecimentos. A pedagogia, mais o afeto, nos dá disposição para contribuir na formação dos alunos, cultivando valores e estimulando o autoconhecimento.

\section{A importância dos vínculos afetivos}

Os vínculos afetivos fazem parte do desenvolvimento das pessoas. A vista disso, percebe-se a importância dessas conexões, pois a forma como o sujeito estabelece seus elos afetivos e suas relações com o outro compõe, molda e transforma a sua identidade, seus ideais e modos de ser, ou seja, criar laços contribui para o pleno desenvolvimento da pessoa em diversos aspectos.

É fundamental receber estímulos, cuidado e muito afeto desde pequeno, pois é por meio desta troca que as pessoas desenvolvem suas relações, aprendendo a interagir, a se comunicar, a se posicionar, iniciando a competência de desenvolver a empatia. Partindo deste ponto identificamos o porquê de compreender a afetividade como contribuinte na relação entre o professor e o aluno. Segundo Rossini (2001), "se o ser humano não está bem afetivamente, sua ação como ser social estará comprometida, sem expressão, sem força, sem vitalidade. Isto vale para qualquer área da atividade humana, independente de idade, sexo e cultura.

É por meio dessa construção afetiva e acolhedora que as pessoas se sentem seguras e disponíveis para as atividades com interações com o outro e, consequentemente, surge o desenvolvimento de suas potencialidades. A busca de proximidade é o maior sinal de que o vínculo foi instaurado, e isto os faz se sentir seguros com o novo e com o ambiente que o cerca.

\section{O afetivo e o cognitivo}

A afetividade e a aprendizagem são dois elementos que não podem ser vistos de forma fragmentada no contexto da educação e no processo de ensino. O papel da afetividade é de extrema importância para a construção do conhecimento, e de influência nos fundamentos que garantem ao aluno um ensino de qualidade. $\mathrm{O}$ afeto e a cognição são conceitos indispensáveis e indissociáveis, necessários à formação dos processos psicológicos (BORBA e SPAZZIANI, 2007). O cognitivo está ligado à construção do conhecimento, do pensamento crítico e reflexivo e, de forma associada à afetividade, torna- 
se um fator essencial para o pleno desenvolvimento do intelecto da criança, na tentativa de melhorar a qualidade e eficiência do ensino-aprendizagem.

Snyders (1986) nos explica que a educação afetiva deveria ser a primeira preocupação dos educadores, já que é um elemento que condiciona o comportamento, o caráter e a atividade cognitiva da criança. Para o autor, quando se ama o mundo, esse amor ilumina e ajuda a revelá-lo e a descobri-lo.

Os vínculos afetivos podem fazer com que tanto os profissionais da educação quanto os alunos possam observar o cotidiano escolar e a vida com mais humanidade, alicerçando relações humanas mais construtivas e baseadas em atitudes altruístas. $\mathrm{O}$ afeto é uma necessidade hoje, não só para aproximar professores de alunos, mas uma forma de esperança que possa resgatar aqueles que muitas vezes são rejeitados pela sociedade, com o objetivo de dar oportunidades e condições melhores de sobrevivência e convívio.

A falta desta afetividade pode interferir no cognitivo. A ausência da mesma na vida da criança traz consequências para o desenvolvimento cognitivo. De acordo com Corrêa (2008), a afetividade é algo que deve estar sempre presente na sala de aula, embora nem sempre seja levada em consideração. Fundamentado na ideia que o ser humano deve ser visto como um todo é de extrema importância considerar o papel da afetividade no desenvolvimento psicológico e na formação de conhecimentos cognitivos/afetivos.

Atualmente no ambiente escolar observa-se, com frequência, a falta de respeito, insensibilidade, indisciplina, e atitudes e ações hostis que também estão além da escola. Fato esse que tem preocupado tanto autoridades educacionais quanto professores, diretores e familiares. Conforme Arantes (2003), a afetividade não modifica as estruturas da inteligência, sendo somente o elemento energético das condutas. Sendo assim, o afeto continua sendo a melhor maneira de apaziguar esses conflitos, pois quando um professor consegue construir uma boa relação com o aluno, haverá uma mudança sentida em todas as áreas, seja no rendimento escolar ou no convívio familiar.

\section{A afetividade na perspectiva de Jean Piaget}

Para Piaget (2014), as construções afetivas e cognitivas se articulam à inteligência, ao julgamento moral, às reações rebeldes, à obediência e aos sentimentos de carinho e temor. O autor acredita que tanto o aspecto afetivo quanto o cognitivo são construídos durante toda a vida do indivíduo e são capazes ainda de abarcar mais elementos, além de sentimentos e emoções. A compreensão que temos a partir desse autor é de que a afetividade, a cognição e 
a motivação, já que estão ligadas ao processo cognitivo e à inteligência, são fatores cruciais para o progresso da aprendizagem dos discentes no cotidiano escolar, uma vez que sem afeto não haveria interesse, nem necessidade, nem motivação. A afetividade é uma condição necessária na constituição da inteligência.

O afeto é indispensável para o desenvolvimento intelectual, pois ele impulsiona as pessoas a agir no objeto do conhecimento. Segundo Piaget (1992), a inteligência age no afetivo. Assim, é possível compreender a relação indissociável entre afetividade e inteligência e é nesse ponto que os estudos do autor contribuem para a nossa pesquisa. Tais postulados corroboram para a compreensão de que a afetividade contribui de maneira significativa para o desenvolvimento dos estudantes.

O processo de formação e enriquecimento afetivo é continuo e inovador, como vimos em Piaget, em que a formação de sentimentos está ligada aos valores sociais, já que são aspectos que se adaptam ao longo do desenvolvimento do indivíduo. Assim, entendemos a partir de Piaget que a afetividade, além de estar ligada à inteligência, pode ser vista também como um caminho para a melhoria do relacionamento professor-aluno. Nos diálogos entre os membros da comunidade escolar o afeto pode ser utilizado como recurso para que as indisciplinas sejam contornadas, as dúvidas sejam sanadas, e o desejo do aluno em aprender e querer crescer esteja ativo e a aprendizagem seja construída.

\section{A afetividade na perspectiva de Lev Vygotsky}

Lev Vygotsky (2003) aprofundou seus estudos sobre o funcionamento dos aspectos cognitivos, suas funções mentais e a consciência. Para o teórico, a consciência aplica-se ao afeto e ao intelecto. O pensamento fica à espera da motivação que inclui o afeto, as necessidades, as emoções e os interesses.

Apesar de não aprofundar seus estudos sobre a afetividade, o mesmo propõe uma abordagem unificada e evidencia a importância das conexões entre o cognitivo e o afetivo nas questões psicológicas. Na opinião de Vygotsky:

A emoção não é uma ferramenta menos importante que o pensamento. A preocupação do professor não deve se limitar ao fato de que seus alunos pensem profundamente e assimilem a geografia, mas também que a sintam. [...] as reações emocionais devem constituir o fundamento do processo educativo. (VYGOTSKY, 2003, p. 121):

Vygotsky acredita que a compreensão do pensamento humano só é possível quando se 
compreende sua base afetiva. Essa construção de Vygotsky vem a corroborar com a presente pesquisa, pois o professor precisa compreender o sentimento de seus estudantes e, num processo de empatia, se colocar em seus contextos. Esse processo é possível mediante uma relação afetiva entre ambos. Paulo Freire também evidencia a importância desse processo quando diz que "o bom professor é o que consegue, enquanto fala, trazer o aluno até a intimidade do movimento do seu pensamento" (FREIRE, 1996, p. 96).

Entretanto, as condições de trabalho dos docentes é um dos fatores que devem ser analisados: as jornadas duplas de trabalho, as condições físicas das escolas, a baixa remuneração, a relação com outros professores, o sistema burocrático imposto, dentre outros. Essas condições trazem como consequência o estresse, a perda de qualidade do ensino, a falta de tempo para refletir sobre sua prática pedagógica, o desgaste físico e mental.

É importante refletirmos a respeito dos fatores que impossibilitam os professores de construir uma relação de afeto com os seus estudantes. Isso acontece por estarem insatisfeitos com as condições de trabalho. A falta de paciência, confiança e compromisso levam a aulas monótonas e sem planejamento. Os professores tem o papel de facilitadores e não apenas um transmissor de conteúdos como na era tradicionalista. É importante postular que o professor é figura essencial no processo educacional, devendo agir como mediador entre o aluno e o conhecimento.

\section{A afetividade na perspectiva de Paulo Freire}

Estamos cada vez mais vivendo em uma sociedade onde a desumanização, o preconceito e a discriminação têm ganhado força. Mas como podemos mudar esta realidade tão emergente? À luz de nossa compreensão nas contribuições de Paulo Freire, esse desafio pode ser enfrentado a partir da educação e da afetividade, qualificando o trabalho do professor, o ensinar como um ato de amor e natureza transformadora. Paulo Freire discute a educação como prática de liberdade. Ele acredita que a educação é um ato de amor, e amor também é diálogo (FREIRE, 1987, p. 79-80).

A relação pedagógica, quando perpassa pelos caminhos da afetividade, abrem portas e oportuniza o desenvolvimento da educação como prática de humanização, de liberdade e expressão. É na relação com o outro que o indivíduo pode crescer como pessoa e estar em processo constante de construção. É importante resgatar o que ainda resta de bom e, quando colocamos afeto em tudo aquilo que fazemos, dá um novo brilho, uma nova perspectiva aos 
resultados que virão.

Freire (1997), além de afirmar a importância dos componentes afetivos na construção do conhecimento, diz que devemos evitar o medo dos nossos sentimentos, de nossas emoções, dos nossos desejos.

A educação através do afeto busca a construção de cidadãos mais equilibrados, com oportunidades iguais, de crescimento pessoal e intelectual, respeitando as vivências e realidades dos alunos. É preciso investir e acreditar nas potencialidades destes alunos, transmitindo coragem para que os mesmos possam enfrentar suas dificuldades e superar limites.

É visível que o pensamento de Lev Vygotsky e Paulo Freire se aproximam muito, pois ambos tratam da autonomia do aluno em sala de aula, dissertam sobre a influência do meio social e cultural na formação de um sujeito, promovendo o desenvolvimento humano.

\section{A afetividade na perspectiva de Henri Wallon}

Henri Wallon (1995) enxerga o afeto como elemento essencial para o funcionamento do corpo. $\mathrm{O}$ afeto tem o poder de encorajar, de motivar, e isso contribui para o desenvolvimento do indivíduo. E qual a importância do afeto para a criança? É importante, pois a criança sente a necessidade de se sentir segura para assim desenvolver o seu aprendizado.

O teórico também acredita que o professor deve ter consciência de seus atos, pois são espelhos, figuras que possuem grande influência na vida dos educandos e são muito significativos nestes processos. A relação entre professor e aluno deve ser alimentada pelo afeto, considerando um pilar estruturante para a contribuição do desenvolvimento individual.

Wallon debruçou-se em seus estudos sobre a afetividade e as emoções e postulou uma diferença em que a emoção é vista como um elemento mediador entre o orgânico e o psíquico e a afetividade é vista como um momento mais tardio do desenvolvimento. A afetividade passa a ser referida por ele como a capacidade, a disposição do ser humano de ser afetado pelo mundo e por sensações que possam ser agradáveis ou não.

A afetividade consegue definir a forma com que as pessoas enxergam o mundo. Todos os acontecimentos e fatos que houve na vida de uma pessoa traz experiências e lembranças por toda a sua história.

Segundo Wallon (1999), em sua teoria psicogenética o indivíduo é um ser corpóreo, concreto e deve ser visto como tal, ou seja, seu domínio cognitivo, afetivo e motor fazem 
parte de um todo: a própria pessoa.

Isso pressupõe que a criança não pode ser percebida de forma fragmentada. A presença ou ausência do afeto determina a forma com que um indivíduo se desenvolverá. Define também a autoestima das mesmas a partir da infância, pois quando uma criança desde pequena é escutada, observada e valorizada, certamente será mais autônoma e crítica em relação ao que pensa, conseguindo desenvolver segurança e determinação. Ou seja, essa visão é importante para o presente trabalho, pois ela ressalta o valor da afetividade nas relações professor-aluno como contribuinte ao desenvolvimento individual de aprendizagem de cada aluno.

\section{O papel da afetividade na relação professor-aluno}

Vivemos em constantes transformações sociais e essas mudanças ocorrem nas escolas também. Antes o professor era visto como a principal fonte de conhecimentos e os alunos apenas meros receptores dos conhecimentos transmitidos pela autoridade que ficava na frente da turma, num contexto bem tradicional. Com as mudanças pedagógicas o professor hoje é visto como mediador no processo de aprendizado, pois, conforme Silva (2007), ensinar pressupõe um aprendizado.

Diante disto, o papel do professor é de facilitar este processo de ensino, a fim de mostrar como se adquire, como que se pode construir conhecimento, permitindo que os alunos ganhem confiança em si mesmos a ponto de aprenderem até por conta própria, em um mundo cada vez mais tecnológico e avançado. É esperado que os professores sejam multifacetados e que consigam equilibrar o tradicional com as inovações que o mundo contemporâneo anda trazendo.

A relação entre professor e aluno é fundamental para o processo de ensino e aprendizagem. Esta relação compactuada com a afetividade pode desenvolver melhores resultados. O professor é quem estabelece a mediação entre o aluno e o conhecimento. Se a mesma se dá de maneira prazerosa, lúdica e criativa, o aluno alcança uma maior gama de conhecimento. A partir disso ele pode usar esses conhecimentos construídos na sua vida futura, sendo assim, a importância da relação de afetividade entre o aluno e o professor é muito evidente na construção do conhecimento.

A relação entre professor e aluno e a construção de um ambiente afetivo na sala de aula começa desde o primeiro contato. Ambos ficam ansiosos e com expectativas por esse momento. Conforme explica Dantas (1994), o professor pode conduzir esse processo e 
ajudar os estudantes, já que o medo, a angústia, a ansiedade e a frustração, são sentimentos que desgastam o aluno, e a serenidade e a tranquilidade dos professores auxiliam na redução, ou até eliminação desses sentimentos desagregadores.

Diante disto, é notório que as primeiras palavras ditas pelo professor deixam impressões e elas podem ser positivas ou negativas. Se neste primeiro momento o diálogo ocorrer de forma amigável, cheio de sorrisos e afetos, abrem-se portas para uma boa convivência, contribuindo para a aprendizagem. Mas se o professor falar palavras duras, a partir desse momento nasce uma barreira entre professor e aluno, impedindo o crescimento pessoal dos mesmos. É no primeiro encontro e através da afetividade que é possível abrir canais de comunicação que possam propagar mudanças significativas e evitar possíveis bloqueios de aprendizagem.

Nessa relação há uma incompatibilidade entre emoção e atividade intelectual que Wallon (1995) chama de antagonismo de bloqueio. O autor também diz que quando não são satisfeitas as necessidades afetivas, estas resultam em barreiras para o processo ensinoaprendizagem e, portanto, para o desenvolvimento, tanto do aluno como do professor.

Um fator importante nesse processo é ouvir o que os alunos têm a dizer, dando oportunidade para que os mesmos se expressem, para que se sintam importantes, estimulando sua autoconfiança, autonomia e criticidade. A partir do momento que o professor usa da afetividade como elemento importante em sua metodologia, perpassa a confiança que os alunos buscam. E é nesses momentos que os professores devem se atentar aos detalhes, pois numa sala de aula há várias realidades distintas em que as aprendizagens seguem ritmos diversos. É na sala de aula que serão compartilhados problemas, e o professor, através do afeto, pode ajudar esses alunos a percorrer caminhos, tomar decisões e pensar em possíveis soluções para os problemas que possam surgir.

\section{A afetividade no âmbito escolar}

A afetividade é primordial na vida da criança, entretanto, existe uma resistência na valorização da mesma em sala de aula. A fase escolar pode ser particularmente difícil para muitos. É um período que além de desenvolverem habilidades de aprendizagem, irão também interagir com o meio em que vivem. Contudo, na atualidade, a afetividade ainda não é tão valorizada como fator relevante no processo de ensino-aprendizagem nas escolas. O professor muitas vezes evita se envolver afetivamente com seus alunos, pensando erroneamente que a aproximação demasiada com os mesmos levaria a um excesso de 
confiança e ao fracasso do processo de aprendizagem. Muitas vezes o fracasso escolar pode estar relacionado à forma como as crianças e adolescentes são tratadas em casa, na escola, e no meio social.

Entende-se que o educando precisa se sentir importante no ambiente escolar, pois esse sentimento lhe transmite a mensagem de que sua presença é crucial, de que ali há alguém que se importa com ele e isso contribui para o desenvolvimento de uma consciência crítica e transformadora.

Segundo Fernández (1991), toda aprendizagem é repleta de afetividade, já que ocorre a partir de interações sociais. É por meio dos processos de interação que o ser humano se transforma num sujeito social, em que se permite desenvolver a comunicação, estabelece contato, cria redes de relações, resultando em determinados comportamentos.

Os parâmetros Curriculares Nacionais (1997, p. 107-108) apresentam a importância de o ensino fundamental trabalhar a formação integral dos estudantes, que inclui temas morais, o respeito mútuo, a justiça, o diálogo, a solidariedade e, sobretudo, as capacidades afetivas.

Sendo assim, entendemos que não se pode desenvolver um bom trabalho educativo, nem oportunizar ao aluno uma aprendizagem de qualidade significativa, sem que a afetividade esteja inserida nestas circunstâncias.

Nesse viés, se faz necessário que toda comunidade escolar esteja preparada e aberta para contribuir com a aprendizagem dos envolvidos de forma empática e flexível, exercendo com amor a sua função e permitindo se adaptar às necessidades dos educandos. Todavia, entende-se que é preciso investir em formações continuadas, com o foco na afetividade no âmbito escolar, abarcando o desenvolvimento de estratégias que conduzam a dinâmica na sala de aula, um clima de respeito, confiança e segurança, colaborando com o desenvolvimento e a singularidade integral do discente.

\section{METODOLOGIA}

Nossa pesquisa é de abordagem bibliográfica qualitativa do tipo exploratória, que de acordo com Denzin e Lincoln (2006), envolve uma abordagem interpretativa do mundo, o que significa que seus pesquisadores estudam as coisas em seus cenários naturais, tentando entender fenômenos em termos dos significados que as pessoas e eles conferem.

$\mathrm{O}$ estudo foi realizado em três etapas. A primeira consistiu em uma busca por trabalhos que tratassem sobre afetividade no âmbito escolar. As pesquisas foram realizadas 
nas plataformas Scielo, CAPES, Google Acadêmico e Anped, a partir dos termos: afetividade, escola, relação professor-aluno. Esses trabalhos foram selecionados a partir de seus resumos. Após essa primeira seleção, os trabalhos foram lidos, seguindo as etapas sugeridas por Gil (2008), na qual identificamos as informações e os dados constantes nos materiais. Estabelecemos relações entre essas informações e o problema proposto e analisamos a consistência das informações e dados apresentados pelos autores.

A segunda etapa consistiu na redação do texto a partir de nossas análises. Para Gil (2008), a redação do texto consiste na expressão literária do raciocínio desenvolvido no trabalho.

A terceira etapa consistiu na construção de um quadro e análise. Essa construção demandou alguns aspectos para alcançarmos nossos objetivos de pesquisa. Esses aspectos foram unitalizados, conforme metodologia proposta pela Análise Textual Discursiva, que é um processo que se inicia com uma unitarização em que os textos são separados em unidades de significado que "podem ser tanto as palavras, frases, temas ou mesmo os documentos em sua forma integral”. (MORAES; GALIAZZI, 2006).

Para analisarmos dados coletados na bibliografia pesquisada nos debruçamos nos conceitos da afetividade no âmbito pedagógico e na relação educativa estabelecida entre professor e aluno na sala de aula.

\section{ANÁLISES E RESULTADOS}

As informações extraídas foram confrontadas com nosso referencial teórico e os conceitos trazidos a este trabalho. Esta análise nos indicou que a afetividade na relação entre professor e estudantes é de fato um aspecto fundamental para o desempenho do processo ensino-aprendizagem.

Descobrimos, também, a partir da análise dos artigos selecionados, alguns fatores que podem impedir o comportamento afetivo dos docentes em relação a seus estudantes e a partir das unidades de significados e suas perspectivas. (MORAES, 1999).

$\mathrm{Na}$ perspectiva de alguns artigos foi possível observar que problemas pessoais, didáticos, ambiente desfavorável à expressão afetiva, a baixa remuneração, as condições de jornadas duplas de trabalho e o sistema burocrático imposto, dentre outras variáveis, podem dificultar o processo de ensino-aprendizagem.

A falta de diálogo entre educador e educando seria uma das dificuldades para a construção de uma relação afetiva entre professores e estudantes, seja por falta de interesse 
ou por falta de estímulo. Freire (1987) acredita na educação como prática de liberdade e de amor, e é nesse ponto que observamos a importância da afetividade através do diálogo na relação do professor-aluno.

Muitos professores hesitam em ter uma relação com a afetividade com seus alunos, acreditando que só assim conseguem manter os limites com o uso de autoridade, excesso de conteúdo e preocupação em cumprir o seu planejamento, o que muitas vezes deixa o ambiente de ensino estressante para ambos. Uma educação com afeto busca a construção de cidadãos mais equilibrados, com oportunidades iguais, de crescimento pessoal e intelectual, procurando respeitar as vivências e realidades dos alunos.

Há ainda os professores que não desenvolvem um comportamento afetivo em relação aos estudantes porque optam por metodologias reducionistas, ou seja, metodologias que não enxergam os estudantes como indivíduos com sensibilidade.

De fato, por muitos anos o processo educacional que se estabeleceu no Brasil era mediado por uma relação que desconsiderava totalmente os estudantes, seus contextos, fragilidades, emoções. Era uma educação que se preocupava apenas com a transmissão do conteúdo.

Segundo Vygotsky (2003), a preocupação do professor não deve se limitar ao fato de que seus alunos pensem profundamente e assimilem a disciplina, mas também que a sintam. É importante que o professor compreenda o sentimento dos seus estudantes e com empatia se coloque em seus contextos.

Diante dos resultados obtidos foi possível compreender a afetividade em seus principais contextos, pois é por meio dos processos de interações, que o ser humano se transforma num sujeito socialmente crítico.

Foi possível compreender também a importância dos vínculos afetivos e o valor dessas conexões, pois a relação com o outro contribui para o pleno desenvolvimento da pessoa em diversos aspectos. Segundo Rossini (2001), se o ser humano não está bem afetivamente, sua ação como ser social estará comprometida, sem expressão, sem força, sem vitalidade. Uma construção afetiva e acolhedora pode fazer com que as pessoas se sintam seguras e disponíveis para realizar atividades de interação com o outro. Wallon (1995) enxerga o afeto como elemento essencial para o funcionamento do corpo. O afeto tem o poder de encorajar, de motivar. 


\section{CONSIDERAÇÕES FINAIS}

O presente trabalho teve como objetivo investigar a afetividade na relação professoraluno, por meio de uma pesquisa qualitativa, realizada através de um estudo bibliográfico. A partir dessa metodologia foi possível compreender que o processo de ensino e aprendizagem não ocorre de forma isolada de afeto, visto que o docente e o discente estão em constante convívio.

A afetividade presente na relação dos indivíduos foi considerada um agente incentivador que perpassa todo este processo, representando aspectos significativos no desempenho educacional, pois é através da relação afetiva que as pessoas se sentem seguras e estimuladas para a construção de conhecimentos, superando suas dificuldades.

Após identificarmos, a partir dos artigos selecionados, alguns fatores que impedem um comportamento afetivo do professor em relação aos estudantes, reafirmamos com esta pesquisa a importância desta temática e a necessidade de aprofundamento em estudos posteriores, pois além de ser importante no cenário educacional, a afetividade tem grande influência no processo educacional e a forma que ela acontece pode ser decisiva na visão de mundo e de indivíduo criada pelo aluno.

\section{REFERÊNCIAS}

ARANTES, Valeria Amorim (org.). Afetividade na escola: alternativas teóricas e práticas. São Paulo: Summus, 2003. (Coleção na escola: alternativas teóricas e práticas).

BRASIL. Parâmetros Curriculares Nacionais (PCN). Secretaria de Educação Fundamental. Brasília: MEC/SEF, 1997.

CORRÊA, P. R. A dimensão do ser humano: contribuições a partir de Piaget. São Carlos, 2008, 48f. TCC (Licenciatura em Pedagogia). Universidade Federal de São Carlos.

DANTAS, H. Afetividade e a construção do sujeito na psicogenética de Wallon. In: La Taille, Y., DANTAS, H., OLIVEIRA, M. K. Piaget, Vygotsky e Wallon: teorias psicogênicas em discussão. São Paulo: Summus Editorial Ltda, 1992.

DENZIN, N. K.; LINCOLN, Y. S. Introdução: a disciplina e a prática da pesquisa qualitativa. In: DENZIN, N. K.; LINCOLN, Y. S. (Orgs). O planejamento da pesquisa qualitativa: teorias e abordagens. 2. ed. Porto Alegre: Artmed, 2006.

FERNÁNDEZ, Alicia. A inteligência aprisionada. Porto Alegre: Artes Médicas, 1991. introdução aos parâmetros curriculares nacionais/ Secretaria de educação fundamental: Brasília: MEC/SEF, 1997.p 107-108. 
FREIRE, Paulo. Pedagogia da Autonomia. 25. ed. São Paulo: Editora Paz e Terra, 1996.

GIL, Antônio Carlos. Métodos e técnicas de pesquisa social. 6. ed. - São Paulo: Atlas, 2008.

LEITE, Sérgio Antônio da Silva. Afetividade nas práticas pedagógicas. Universidade Estadual de Campinas, Campinas, SP, Brasil, v. 20, n. 2, 2012.

LOOS-SANT'ANA, Helga; GASPARIM, Liege. Investigando as interações em sala de aula: Wallon e as vinculações afetivas entre crianças de cinco anos. Educação em Revista, Belo Horizonte, v. 29, n. 03, p. 199-230, jul. 2013.

MAHONEY A. Alvarenga. Concepção de afetividade. Psicologia da Educação, da Pontifícia Universidade Católica de São Paulo (PUC-SP), 2012.

MORAES, R.; GALIAZZI, M. C. Ciência \& Educação, v. 12, n. 1, p. 117-128, 2006.

MORAES, Roque. Análise de conteúdo. Revista Educação. Porto Alegre, v. 22, n. 37, p. 7 32, 1999.

LOOS-SANT'ANA, Helga; GASPARIM, Liege. Investigando as interações em sala de aula: Wallon e as vinculações afetivas entre crianças de cinco anos. Educação em Revista, Belo Horizonte, v. 29, n. 03, p. 199-230, jul. 2013.

MAHONEY A. Alvarenga. Concepção de afetividade. Psicologia da Educação, da Pontifícia Universidade Católica de São Paulo (PUC-SP), 2012.

MORAES, R.; GALIAZZI, M. C. Ciência \& Educação, v. 12, n. 1, p. 117-128, 2006.

MORAES, Roque. Análise de conteúdo. Revista Educação. Porto Alegre, v. 22, n. 37, p. 732, 1999.

PANIZZI, Conceição Aparecida Fernandes Lima. A relação afetividade-aprendizagem no cotidiano da sala de aula: enfocando situações de conflito. Agência Financiadora: GT: Educação Fundamental/n.13, Porto, Portugal, n. 13, p. 1-17, 2004.

PEREIRA, Maria José de Araújo; GONÇALVES, Renata. Afetividade: caminho para aprendizagem. Revista Alcance: Revista eletrônica de EAD da UNIRIO, Rio de Janeiro, v. 1, p. 12-18, 2010.

PIAGET, Jean. Relações entre a afetividade e a inteligência no desenvolvimento mental da criança. Tradução e organização: Cláudio J. P. Saltini e Doralice B. Cavenaghi. Rio de Janeiro: Wak, 2014.

RIBEIRO, Marinalva Lopes. A afetividade na relação educativa. Estudos de Psicologia (campinas), [s.1.], v. 27, n. 3, p. 403-412, set. 2010. FAPUNIFESP (SciELO).

ROSSINI, Maria. Pedagogia afetiva. 7. ed. Petrópolis: Vozes, 2001. 
SOUSA, Rayara Nogueira de; RAMOS, François Silva; SOUSA, Francisca Semirames Nogueira de. A afetividade e sua influência no processo da a prendizagem nas crianças: Revista Expressão Católica, Rev. Expr. Catól.; V. 7, N. 2; Jul - Dez; 2018; ISSN: 2357-8483, v. 7, p. 7-13, 17 dez. 2018.

SYNDERS, Georges. A alegria na escola. São Paulo: Manole, 1998.

VIEIRA, M. M. F.; ZOUAIN, D. M. Pesquisa qualitativa em administração: teoria e prática. Rio de Janeiro: Editora FGV, 2005.

VYGOTSKY, L. S. Psicologia Pedagógica. Porto Alegre: Artmed, 2003.

WAGNER, Maiby Gisele; TRUGILLO, Edneuza Alves. A relação professor-aluno na construção do conhecimento. Revista Eventos Pedagógicos: REP's, Mato Grosso, v. 2, n. 1 (2. ed. rev. e aum.), p. 200-209, jan./jul. 2011.

LA TAILlE, Y. De; OLIVEIRA, M. K. De; DANTAS, H. Piaget, Vygotsky e Wallon: teorias psicogenéticas em discussão. São Paulo, 1992.

WALLON. Algumas contribuições da psicogenética atividade educativa. Revista de educação da A.E.C., Brasília, v. 23, nº 91, p. 45-51, abr/jun.

WALLON, H. As origens do pensamento da criança. São Paulo: Manole, 1986. 